\title{
Terpene Cyclizations inside a Supramolecular Catalyst: Leaving Group-Controlled Product Selectivity and Mechanistic Studies
}

\author{
Qi Zhang', Lorenzo Catti ${ }^{\mathrm{a}}$, Jürgen Pleiss ${ }^{\mathrm{c}}$, Konrad Tiefenbacher ${ }^{\mathrm{a}, \mathrm{b} *}$ \\ ${ }^{a}$ Department of Chemistry, University of Basel, St. Johanns-Ring 19, CH-4056 Basel, Switzerland \\ ${ }^{b}$ Department of Biosystems Science and Engineering, ETH Zürich, Mattenstrasse 26, CH-4058 Basel, Swit- \\ zerland \\ ${ }^{c}$ Institute of Technical Biochemistry, University of Stuttgart, Allmandring 31, D-70569 Stuttgart, Germany
}

\begin{abstract}
The tail-to-head terpene cyclization is arguably one of the most complex reactions found in nature. The hydrogen bondbased resorcinarene capsule represents the first man-made enzyme-like catalyst that is capable of catalyzing this reaction. Based on noncovalent interactions between the capsule and the substrate, the product selectivity can be tuned by using different leaving groups. A detailed mechanistic investigation was performed to elucidate the reaction mechanism. For the cyclization of geranyl acetate, it was found that the cleavage of the leaving group is the rate determining step. Furthermore, the studies revealed that trace amounts of acid are required as co-catalyst. A series of control experiments demonstrate that a synergistic interplay between the supramolecular capsule and the acid traces is required for catalytic activity.
\end{abstract}

\section{Introduction}

Terpenes constitute one of the largest classes of natural products which is characterized by its enormous structural diversity. ${ }^{1}$ Terpene natural products display a broad range of biological activities and are important for the treatment of human diseases. For instance, the sesquiterpene $\operatorname{artemisinin}^{2}(11$, Scheme 1) and its derivatives are still used as the standard treatment against Plasmodium falciparum malaria. Another prominent example is the diterpene taxol/paclitaxel ${ }^{3}$ (14, Scheme 1) which is used in the treatment of various types of cancer. Unfortunately, synthetic chemists are unable to produce these important terpene drugs in large amounts due to limitations of the current tools of synthetic organic chemistry. Large scale syntheses of complex terpenes are usually hampered by the long synthetic sequences and the extensive purification procedures required. Therefore, these drugs are produced via semisynthetic routes which rely upon the biomachinery to build up the complex and functionalized carbon skeletons. ${ }^{2,4}$ In nature, cyclic terpenes are produced by enzymes, termed terpene cyclases, which are able to bind the acyclic terpene substrates in a defined conformation. These enzymes can be divided into two classes which differ in the way the cationic cyclization cascade is initiated. ${ }^{5}$ In class I cyclase enzymes, an allylic cation is generated by the cleavage of a diphosphate leaving group with the help of magnesium ions. Class II cyclase enzymes, on the other hand, initiate the cyclization by direct protonation of a double bond or an epoxide. Organic chemists have referred to these two different cyclization pathways also as tail-to-head terpene (THT) and head-to-tail terpene (HTT) cyclization, respectively. ${ }^{6}$ In the HTT cyclization, the substrate is activated by protonation at the prenyl head group and the cyclization reaction proceeds in a concerted fashion, mainly yielding products featuring a decalin framework. This type of cyclization has been intensively studied and successfully reproduced in solution. ${ }^{7}$ In the tail- to-head terpene (THT) cyclization, the activation at the tail end leads to the formation of a susceptible allylic cation, which is then chaperoned by the terpene cyclase to undergo a variety of different reactions (rearrangements, cyclizations, elimination, substitution) to produce a diverse variety of products in a selective fashion. Man-made catalysts for the tail-to-head terpene cyclization are lacking. The following two problems are generally encountered in solution: 1) due to the absence of stabilization, the cationic intermediates are prematurely quenched by nucleophilic attack or elimination, resulting in acylic or monocyclic structures; 2 ) in contrast to the defined conformation of the substrate within an enzyme pocket, substrates in bulk solution adopt random conformations, giving rise to complex product mixtures.

In this context, supramolecular capsules held together by either metal-ligand interactions, ${ }^{8}$ hydrogen bonds, ${ }^{9}$ or mainly the hydrophobic effect ${ }^{10}$ serve as promising candidates to tackle the current limitations. Resembling to some extent enzyme pockets, the cavities of supramolecular capsules provide a specific chemical environment different from the exterior medium. In several cases catalytic conversions inside supramolecular structures were described. ${ }^{11}$ The limited space within their cavities can influence substrate conformations like in natural enzymes. Our group ${ }^{12}$ and the groups of Scarso and Strukul ${ }^{13}$ reported the realization of this strategy utilizing the resorcinarene capsule I, first reported by the Atwood group in $1997 .{ }^{14}$ Capsule I self-assembles via hydrogen bonds from six resorcinarene units $\mathbf{1 5}$ and eight water molecules in apolar solvents (Figure 1). It features an octahedral-shaped cavity of approx. $1.4 \mathrm{~nm}^{3}$ volume. Guest exchange is usually facile and is believed to occur via a portal mechanism, where one of the resorcinarene units dissociates. ${ }^{15}$ Organic ammonium ions display a high affinity for capsule I due to cation- $\pi$ interactions with the 
Scheme 1. Biosynthetic pathways towards cyclic terpene natural products. (a) Proposed mechanism for the THT-cyclization of geranyl pyrophosphate (1) and a selection of cyclic products. (b) Formation of the polycyclic sesquiterpene artemisinin (11) from farnesyl pyrophosphate (9). (c) Formation of the polycyclic diterpene taxol (14) from geranylgeranyl pyrophosphate (12).

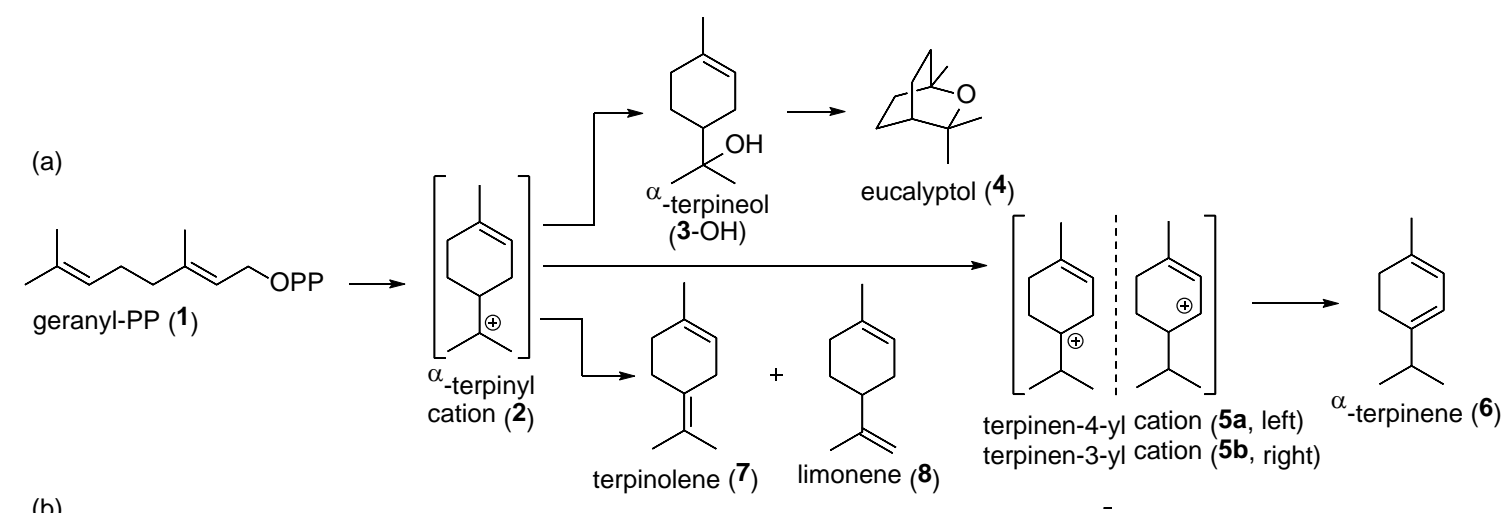

(b)

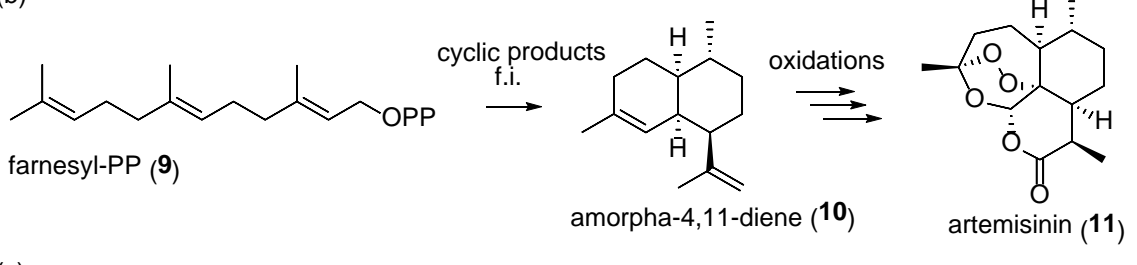

(c)
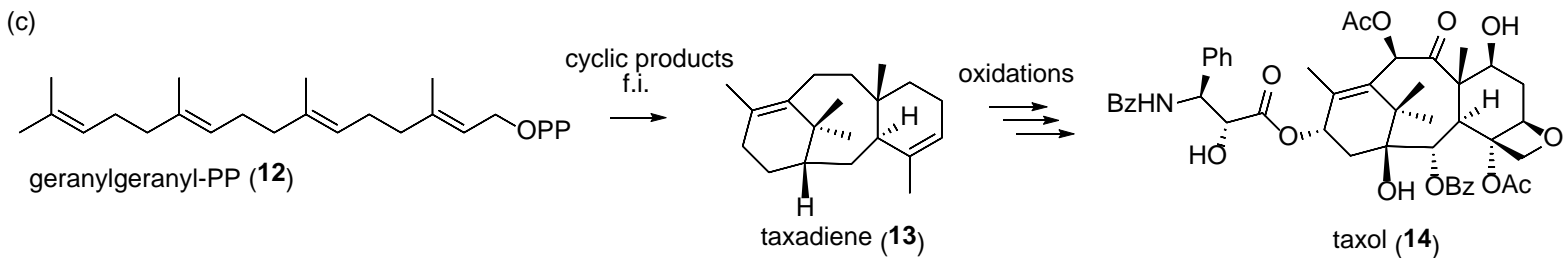

aromatic cavity walls. ${ }^{14 \mathrm{~b}, 16}$ Taking advantage of its capability to stabilize cationic guests, the tail-to-head terpene cyclization was realized for the first time with an artificial catalytic system. ${ }^{12 c} \mathrm{~A}$ selective cyclization reaction was achieved with geranyl acetate (GOAc, 20, Figure 3c) as the substrate. Herein, we expand our initial report to broaden the substrate scope and report on detailed mechanistic investigations.

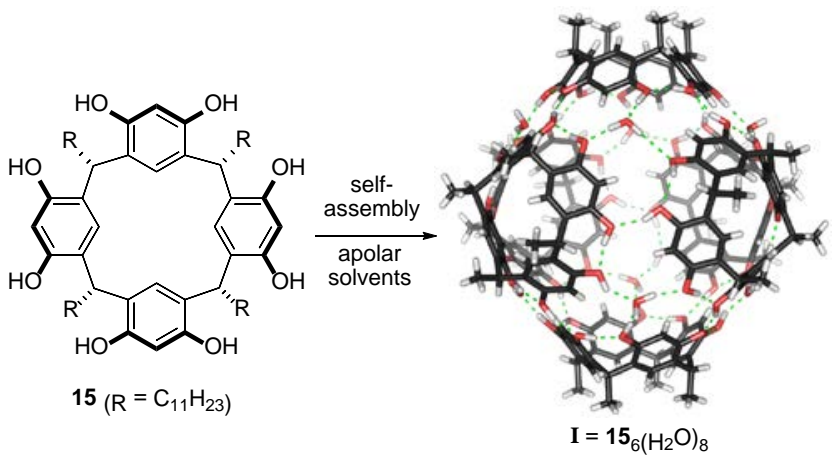

Figure 1. Structure of the resorcinarene capsule I. Six copies of resorcinarene $\mathbf{1 5}$ self-assemble together with eight water molecules via hydrogen bonding to a hexameric capsule in apolar solvents. The capsule is capable of stabilizing cationic guests inside its cavity via cation- $\pi$ interaction. (R groups omitted for clarity)

\section{Results and discussion}

Optimization of reaction conditions. Fluctuations in the reaction rate observed during the course of this study prompted us to examine the reaction conditions more closely. It was found that the rate of the cyclization reactions varied strongly depending on the batch and the supplier of the deuterated chloroform that was used as the solvent. Most surprisingly, the reaction in deuterated chloroform, which was stored over silver foil yielded only trace amounts of cyclic products under otherwise identical conditions. Since silver foil is used as a radical scavenger to suppress the photodegradation of chloroform, it was proposed that DCl-traces in chloroform might accelerate the cyclization reaction. A revealing observation was made when comparing the ${ }^{1} \mathrm{H}$ NMR spectra of the resorcinarene capsule I dissolved in different batches of chloroform (SI-Figure 14). The phenolic OH-groups of the resorcinarene capsule I and water displayed sharp signals in chloroform, which was previously stored over silver foil. In contrast, broad peaks were observed for both the phenolic $\mathrm{OH}$-groups and water, when the capsule was dissolved in chloroform without stabilizer. Signal broadening in NMR spectroscopy can be attributed to an increase in the exchange rate between two species, and this phenomenon in turn could be caused by the presence of acidic protons. To obtain further information, we prepared samples of the resorcinarene capsule $\mathbf{I}$ in chloroform with different $\mathrm{DCl}$-contents (1-10 mol\%, Figure 2a). In accordance with the previous observation, the $\mathrm{DCl}$-free sample (chloroform was filtered through basic aluminum oxide to remove traces of acid) showed sharp signals for the phenolic protons (marked with*) and water (marked with $\circ)$. An increase in DCl-content was clearly accompanied by the broadening of the phenol and water signals. These results also finally clarify the report of differently shaped phenolic signals of the resorcinarene capsule in literature. ${ }^{14 b, 16-17}$.

$\mathrm{Next}$, the samples of different capsule-to- $\mathrm{DCl}$ ratios were sub- 
(a)
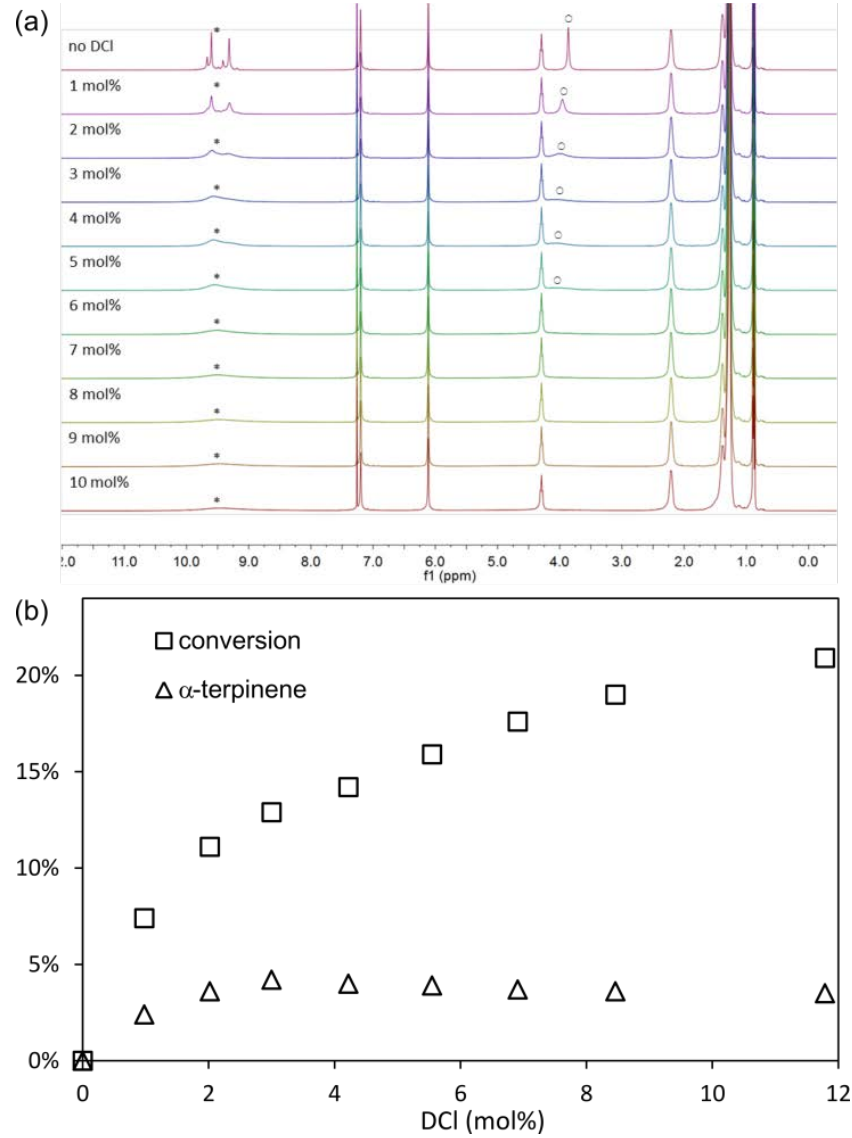

Figure 2. Optimization of the DCl content for the THT cyclization reaction. (a) NMR spectra of the resorcinarene capsule with increasing amounts of $\mathrm{DCl}$ (relative to the substrate). The broadening of the phenolic peaks of the capsule and the water peak in the presence of $\mathrm{DCl}$ traces indicates a faster proton exchange between the capsule and water. The water signals in the samples with more than $5 \mathrm{~mol} \% \mathrm{DCl}$ are too broad to be observed. (b) Influence of the $\mathrm{DCl}$ content on the reaction rate and on the yield of $\alpha$-terpinene (6).

jected to cyclization reactions with GOAc (20) as the substrate (Figure 2b). No reaction was observed in DCl-free chloroform filtered through basic aluminum oxide. The reaction only took place after the addition of DCl. A linear trend could be observed between the reaction rate and the amount of $\mathrm{DCl}$ for the concentration range of $2-9 \mathrm{~mol} \%$. The addition of $3 \mathrm{~mol} \%$ of $\mathrm{DCl}$ was found to be the optimum regarding the yield of $\alpha$-terpinene (6). The addition of more than $3 \mathrm{~mol} \%$ of $\mathrm{DCl}$ did not further facilitate the formation of products. Importantly, when the capsule was omitted, the reaction in solvent containing $3 \mathrm{~mol} \%$ of $\mathrm{DCl}$ did not result in any observable conversion, even after 10 days. This clearly rules out that the acid alone is responsible for the reaction observed. Additionally, all the control experiments performed (vide infra, Table 1) also confirm that the reaction takes place inside the capsule only. The cyclization experiments were also performed using $\mathrm{HCl}$ as the additive. Comparable results were obtained. This is not surprising since a fast proton exchange between phenol and water protons is observed. ${ }^{18}$ These experiments indicate that the capsule and the acid traces work in a synergistic fashion. As indicated by the broadening of the phenol and water signals in the ${ }^{1} \mathrm{H}$ NMR spectra, there is a fast exchange which indicates a protonation of the capsule. The combination of the capsule and acid is somewhat reminiscent of natural enzymes with cofactors. ${ }^{19}$ In this case, the capsule is not able to catalyze the reaction by itself and therefore represents an apoenzyme-like moiety. In other cases the acidity of the capsule is enough for substrate activation. ${ }^{12 a}$ The corresponding holoenzyme is formed upon protonation by acid traces. The transfer of a proton then activates the substrate and the capsule stabilizes the resulting transition states and intermediates to enable the catalytic transformation. This is also consistent with our recent finding on the pyrogallolarene capsule, which is structurally closely related but catalytically inactive. ${ }^{20}$ In light of these results, the lack of stabilization of ion pairs in the pyrogallolarene system is likely the reason for its catalytic incompetence.

Influence of the leaving group on the product selectivity. Our investigation started with the cyclization of the commercially available monoterpene alcohols geraniol $(\mathrm{GOH}, 16$, Figure 3a), linalool ( $\mathrm{LOH}, 17$, Figure $3 \mathrm{~b})$ and nerol $(\mathrm{NOH}, 18$, Figure $3 \mathrm{e})$. Full conversion of each substrate was observed within less than 30 hours when using $10 \mathrm{~mol} \%$ resorcinarene capsule $\mathbf{I}$ as the catalyst in $\mathrm{CDCl}_{3}$ at $30^{\circ} \mathrm{C}$. Cyclization products were identified by comparison of the ${ }^{1} \mathrm{H}$ NMR spectra and the GC traces of the reaction mixtures with authentic monoterpene samples. The cyclization of $\mathrm{GOH}$ (16) bears analogy to the proposed mechanism of terpene biosynthesis: due to the geometric constraint imparted by the (E)-configured double bond, which prevents direct cyclization, $\mathrm{GOH}$ (16) partially underwent an initial isomerization step to form LOH (17) and cyclized mainly to $\alpha$-terpinene (6) and $\alpha$ terpineol (3-OH). The cyclization of $\mathrm{NOH}$ (18) displayed a different reaction course. Within the first 20 hours, $\alpha$-terpineol (3$\mathrm{OH}$ ) was formed as the dominant product, which was further converted to the bicyclic product eucalyptol (4) in good selectivity. This result is quite remarkable, since the formation of eucalyptol from an acyclic substrate has not been achieved in a one-pot cascade reaction utilizing a man-made catalyst before. Eucalyptol synthesis has so far only been realized by subjecting the preformed cyclic $\alpha$-terpineol either to harsh acidic conditions ${ }^{21}$ or by employing a two-step procedure via phenylselenoetherification. ${ }^{22}$

The mechanism of the eucalyptol formation (Scheme 1a) from $\mathrm{NOH}$ (18) within I was studied in more detail. After the formation of the key intermediate $\alpha$-terpineol $(3-\mathrm{OH})$, the $\mathrm{C}-\mathrm{C}$ double bond has to be activated via protonation to initiate the second cyclization (Scheme 2a, grey box). Two possible mechanisms are conceivable for the protonation step: 1) the tertiary alcohol could be protonated first and then transfers the proton to the double bond. This would result in a syn-facial addition of the proton and the $\mathrm{OH}$-group onto the $\mathrm{C}-\mathrm{C}$ double bond. 2) Alternatively, the $\mathrm{C}-\mathrm{C}$ double bond could be protonated directly from either of the two sides of the cyclohexene ring. To clarify the mechanism, deuterium-labelling experiments were performed by replacing all possible proton sources with deuterium ions (Scheme 2a, for details see SI chapter 3.2). If the syn-addition mechanism is operational, the incorporated deuterium atom should be syn to the ether functionality, whereas the latter mechanism would result in a mixture of syn- and anti-stereochemistry. 1-OD-nerol (D-18) and capsule with deuterated phenol groups and deuterated water molecules were prepared via hydrogendeuterium exchange and subsequently submitted to the standard reaction condition. By comparison of the spectra of the isolated eucalyptol with the literature data, ${ }^{23}$ the exclusive synstereochemistry between the deuterium and the ether functionali- 
ty was unambiguously confirmed. This clearly demonstrated that the cyclic ether is formed via proton transfer from the tertiary alcohol to the $\mathrm{C}-\mathrm{C}$ double bond (Scheme 2a), similarly as in natural cyclase enzymes. ${ }^{23}$

Scheme 2. Isotope-labelling experiments with monoterpene alcohols. (a) The syn-addition mechanism is operational in the formation of eucalyptol (4). (b) The experiment of ${ }^{18} \mathrm{O}$-labelled $\mathrm{LOH}\left({ }^{18} \mathrm{O}-17\right)$ indicates that the cleaved leaving group is responsible for the interception of the cationic intermediate.

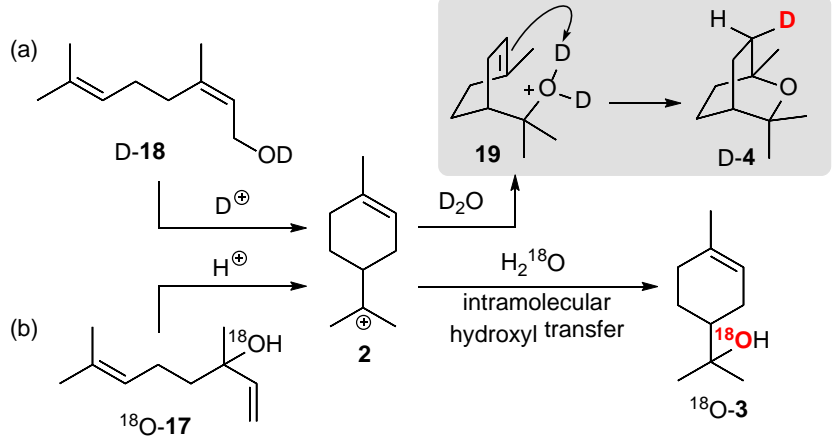

In the cyclization reactions of monoterpene alcohols, $\alpha$-terpineol (3-OH) was detected as a common intermediate, which indicates the premature quenching of the $\alpha$-terpinyl cation (2) (Scheme 1) by nucleophilic attack of water. In principle, the oxygen atom could originate either from the water molecule liberated from the substrate (leaving group) or from one of the eight water molecules which are embedded in the hydrogen bond network of the capsule (Figure 1). To probe the origin of the $\mathrm{OH}$ group in $\alpha$ terpineol $(3-\mathrm{OH}), 3-{ }^{18} \mathrm{OH}$-linalool $\left({ }^{18} \mathrm{O}-17\right)$ was synthesized ${ }^{24}$ and subjected to the cyclization reaction (Scheme 2b). The subsequent GC-MS analysis of the $\alpha$-terpineol formed revealed that approx. $75 \%$ of the oxygen incorporated stems from the leaving group (SI chapter 3.1). Considering the large excess of $\mathrm{H}_{2}{ }^{16} \mathrm{O}$ present in close proximity to the $\alpha$-terpinyl intermediate 2 , this result strongly indicates that the cleaved water molecule predominately served as the nucleophile to form the $\alpha$-terpineol product.

To suppress the premature quenching of cationic intermediates by water, other leaving groups were screened. The acetate leaving group was found to be a suitable choice in this regard. As evidenced by the reaction of GOAc (20, Figure 3c), the linalyl and terpinyl intermediates were no longer observed in the course of the reaction. Instead, the cationic charge was able to propagate via hydride shift to form either the terpinen-4-yl (5a) or terpinen-3-yl cation (5b, Scheme 1a) which finally underwent proton elimination to form $\alpha$-terpinene (6) in good selectivity. This further confirms that in the case of alcohol substrates the water leaving group served as the nucleophile. The water molecules of the hydrogen bond network, however, do not interfere with the cyclization cascade. In the cases of LOAc (21, Figure 3d) and NOAc (22, Figure $3 \mathrm{f}$ ), the premature termination of the cascade reaction was also substantially reduced, and only a small fraction of $\alpha$-terpinyl acetate (3-OAc) was produced initially. It should be noted that a substantial amount of LOAc (21) equilibrated to GOAc (20) prior to cyclization. This may be rationalized by the higher ther- modynamic stability of GOAc (20). In contrast to the reaction of GOAc (20), the cyclizations of NOAc (22) and LOAc (21) displayed lower product selectivities. In the initial phase of the reactions, the formation of terpinolene (7), $\alpha$-terpinene (6), and limonene (8) as main products was observed. The difference in the product spectrum of GOAc (20) and NOAc (22)/LOAc (21) was surprising to us because the reaction paths of all substrates converge at the same intermediate, the $\alpha$-terpinyl cation (2). To investigate this observation in more detail, experiments with fluoro derivatives of NOAc (22) and GOAc (20) were performed. 2Fluoro-derivatives of acyclic monoterpenes were successfully utilized to elucidate reaction mechanisms with cyclase enzymes. ${ }^{25}$ The 2-fluoro substituent destabilizes positive charges at neighboring positions, thereby efficiently slowing down ionizationdependent $\left(S_{N} 1\right.$-type $)$ reaction pathways. Since concerted $\left(S_{N} 2\right.$ type) reaction pathways, on the other hand, still remain viable with the 2-fluoro derivatives, such experiments can be used to elucidate the initial step in the cyclization cascade. Indeed, the investigations of 2-fluorogeranyl acetate and 2-fluoroneryl acetate allowed the clarification of this observation. ${ }^{12 c}$ Utilizing capsule catalyst I under standard conditions, 2-fluorogeranyl acetate failed to show any formation of cyclic terpene products, confirming the required $S_{N} 1$-type initial ionization step. On the other hand, 2-fluoroneryl acetate was converted to cyclic terpene products, providing strong evidence for a concerted $S_{\mathrm{N}} 2$-type initial cyclization step. Additionally, the product spectrum mainly showed the corresponding fluoro derivatives of terpinolene and limonene (F-7 and F-8, respectively. Scheme 3) as products, while the formation of the fluoro derivative of $\alpha$-terpinene (6, which was observed with the regular non-fluorinated neryl acetate substrate) was suppressed. These experiments provide solid evidence that $\alpha$-terpinene $(6)$ is formed mainly via a $S_{N} 1$-type mechanism while terpinolene (7) and limonene (8) are formed via a concerted $S_{N} 2$-type pathway. Due to the constraint of the 2- $(E)$ alkene in GOAc (20), ionization $\left(S_{N} 1\right)$ and isomerization have to precede the cyclization step, which likely allows the cleaved $\mathrm{AcOH}$ to diffuse away from the reaction center before cyclization occurs. However, in the cases of NOAc (22) and LOAc (21), the cleavage of the leaving group and cyclization can occur in a concerted fashion ( $S_{N} 2$ and $S_{N} 2$, respectively). As a result, the highly reactive cationic intermediate is present in direct proximity to the liberated $\mathrm{AcOH}$, which can act as a general base in the deprotonation of the $\alpha$-terpinyl cation 2 , yielding terpinolene (7) and limonene $(8)$ as the products. In case of geranyl substrates, alkylation of the capsule's phenol groups was identified as a side reaction. ${ }^{12 c}$ It seems that the geranyl cation 47 (vide infra, Scheme 4), which has to isomerize to the cisoid-allylic cation 37 (vide infra, Scheme 4) prior to cyclization, is long-lived enough for an attack by one of the capsule's phenol groups. In contrast, the reactions of the neryl and linalyl substrates were not affected substantially by this side reaction; most likely since no isomerization step is required in these cases.

To further clarify the role of the leaving group, the study was expanded to additional derivatives. It was found that the product selectivity of neryl substrates can be biased by the choice of the leaving group. As stated previously, the reaction of $\mathrm{NOH}$ 

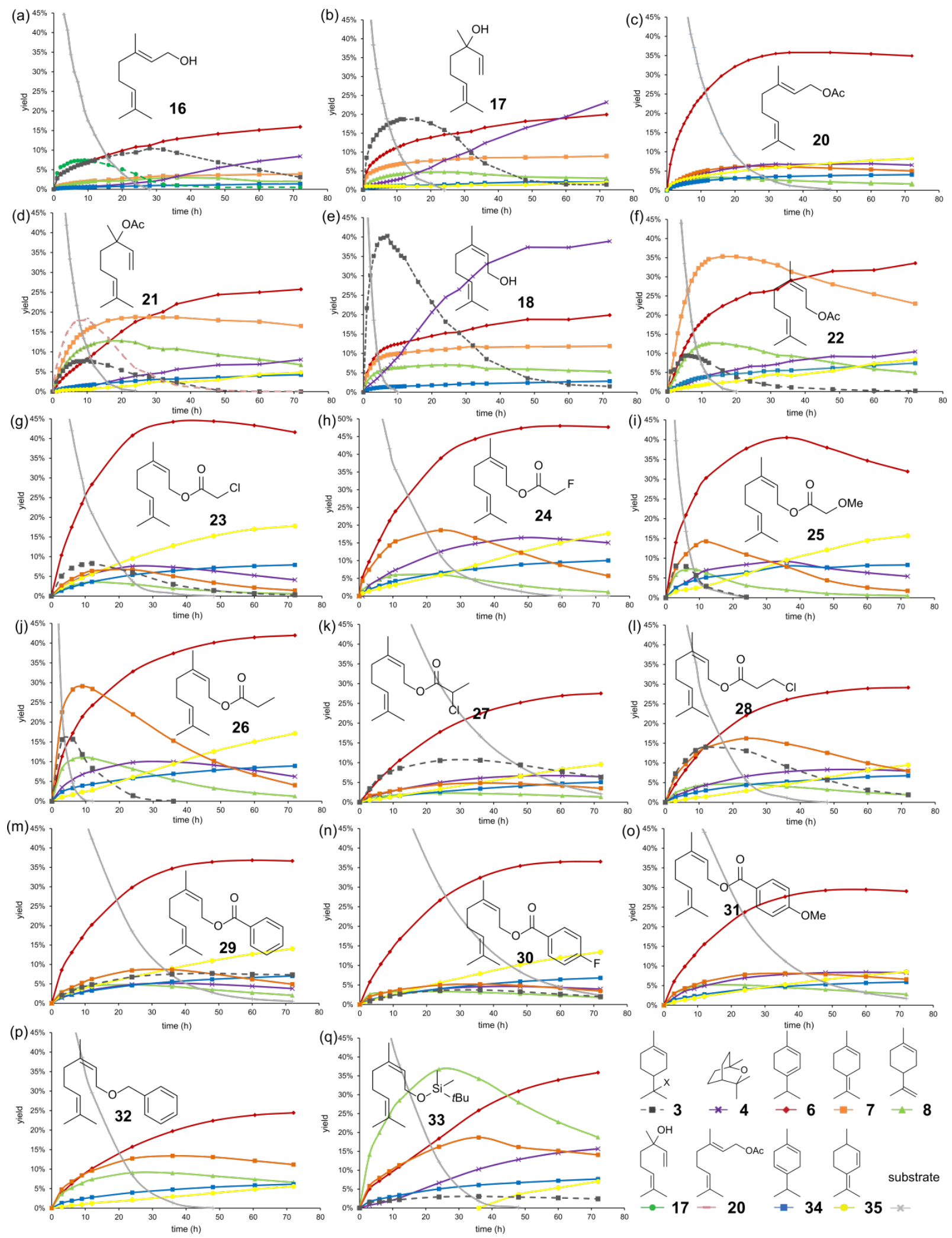

Figure 3. The reaction profiles of $\operatorname{GOH}(\mathbf{1 6}, \mathrm{a}), \mathrm{LOH}(\mathbf{1 7}, \mathrm{b}), \operatorname{GOAc}(\mathbf{2 0}, \mathrm{c}), \mathrm{LOAc}(\mathbf{2 1}, \mathrm{d}), \mathrm{NOH}(\mathbf{1 8}, \mathrm{e})$, NOAc (22, f), neryl chloroacetate (23, $\mathrm{g})$, neryl fluoroacetate $(\mathbf{2 4}, \mathrm{h})$, neryl methoxyacetate $(\mathbf{2 5}, \mathrm{i})$, neryl propionate $(\mathbf{2 6}, \mathrm{j})$, neryl 2-chloropropionate (27, $\mathrm{k})$, neryl 3-chloropropionate $(\mathbf{2 8}, \mathbf{1})$, neryl benzoate $(\mathbf{2 9}, \mathrm{m})$, neryl 4-fluorobenzoate $(\mathbf{3 0}, \mathrm{n})$, neryl 4-methoxybenzoate $(\mathbf{3 1}, \mathrm{o})$ neryl benzyl ether (32, p) and neryl tertbutyldimethylsilyl ether $(33, \mathrm{q})$. The $\alpha$-terpinyl X compounds 3 represent the species which result from the nucleophilic attack of the cleaved leaving group on the $\alpha$-terpinyl cation 2 (Scheme 1). Cyclization reactions were performed in $\mathrm{CDCl}_{3}$ at $30^{\circ} \mathrm{C}$ with a substrate concentration of $33.3 \mathrm{mM}$ and using $10 \mathrm{~mol} \% \mathrm{I}$ as the catalyst. The interception of the cationic intermediate was significantly suppressed by employing acetate as the leaving group ( $\mathrm{a}$ vs. c, b vs. $\mathrm{d}$ and e vs. f). The product profiles of the neryl substrates were highly dependent on the leaving group employed $(\mathrm{e}-\mathrm{q})$. 
(18) mainly yielded eucalyptol (4), while NOAc (22) produced terpinolene (7) as the major product. In an effort to reduce the nucleophilicity of the leaving group, the cyclization of neryl chloroacetate (23, Figure $3 \mathrm{~g}$ ) was investigated. Remarkably, aterpinene (6) was found to be the dominating product throughout the reaction. This was also the case for the reaction of neryl benzoate (29, Figure $3 \mathrm{~m})$. However, when switching to tertbutyldimethylsilyl ether (33, Figure 3q) as the leaving group, limonene (8), which was only a minor component before, became the major species within the first 40 hours.

Scheme 3. Influence of the leaving group on the product selectivity of neryl substrates. The experiments with fluoro derivatives indicate that the neryl substrates of category a likely undergo an ionization step $\left(S_{N} 1\right)$ prior to cyclization, whereas the cyclization of neryl substrates of category $\mathbf{b}, \mathbf{c}$ and $\mathbf{d}$ proceeds in a $\mathrm{S}_{\mathrm{N}} 2$ fashion.

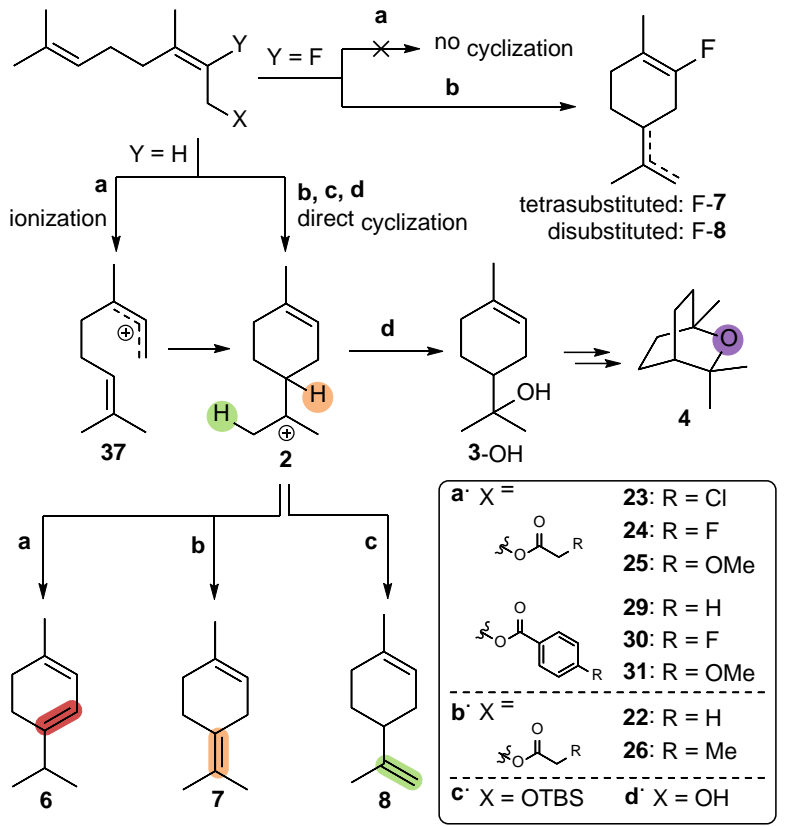

The dominant formation of limonene $(\mathbf{8})$ in the case of the neryl tert-butyldimethylsilyl ether (33) can be rationalized via a kinetic deprotonation effect. The sterically demanding silanol preferentially abstracts the more accessible proton (marked in green in Scheme 3). However, the change in the cyclization behavior of neryl chloroacetate (23) and neryl benzoate (29) remained puzzling. The similarity of their product profiles to that of GOAc (20) may indicate a related reaction mechanism. As previously demonstrated, the high selectivity of the reaction of GOAc (20) results from its $S_{N} 1$-type reaction mechanism. To test whether the same is true for neryl chloroacetate (23) and neryl benzoate (29), the corresponding 2-fluoro derivatives were prepared and subjected to the reaction conditions. The hypothesis was supported by the inertness of 2-fluoro neryl chloroacetate and 2-fluoro neryl benzoate under the standard cyclization condition. Since 2 -fluoro neryl acetate readily produced the corresponding fluoro derivatives of terpinolene and limonene (F-7 and F-8) via the $S_{N} 2-$ mechanism, these results provided strong evidence for a change of the reaction mechanism. It changes from a $S_{N} 2$ to a $S_{N} 1$-type mechanism in case of the neryl chloroacetate and benzoate.

The nucleophilicity of the leaving group does not account for the observed effect, as more electron-deficient (chloroacetate, Figure
$3 \mathrm{~g}$ and fluoroacetate, Figure $3 \mathrm{~h}$ ) as well as more electron-rich (methoxyacetate, Figure 3i) derivatives of the acetate leaving group displayed the higher selectivity for $\alpha$-terpinene associated with a $S_{N} 1$-type mechanism. The propionate leaving group (Figure $3 \mathrm{j}$ ), however, showed a product profile comparable to that of the acetate substrate. Interestingly, all neryl substrates displaying the more selective $S_{N} 1$-type reaction carry additional substituents on the leaving group that allow interactions with the capsule walls via hydrogen bonds $(\mathbf{2 3}, \mathbf{2 4}, \mathbf{2 5})$. Thus, it was proposed that this additional interaction may strengthen the binding of the substrate, resulting in a conformation of the bound substrate that is unproductive for the regular $S_{\mathrm{N}} 2$ reaction pathway of neryl substrates. This hypothesis was supported by binding studies. The inert substrate analog 40 (Figure 4) bearing the chloroacetate group showed a 5.6-fold higher binding affinity to the capsule than that of the acetate counterpart 38. Similarly, a stronger binding was observed for the substrate analog with a fluoroacetate residue 41. However, the substrate analog carrying the propionate group 39 displayed only a moderate binding affinity toward capsule $\mathbf{I}$. This is consistent with its less pronounced bias for the $S_{N} 1$ type reaction mechanism. The effect of the substituent on the leaving group was further examined with neryl 2chloropropionate (27, Figure 3k) and neryl 3-chloropropionate (28, Figure 31). As compared to the reaction of neryl propionate (26), the introduction of the chloro substituent increased the proportion of $\alpha$-terpinene (6) in the product mixture. However, the substrate recognition is also affected by the steric hindrance and the size of the binding motif. Compared to the reaction of neryl chloroacetate (23), the introduction of a methyl group next to the chloro substituent (neryl 2-chloropropionate, 27) or an increase of the chain length of the leaving group (neryl 3chloropropionate, 28) significantly diminished the preference for the $S_{N} 1$-pathway.
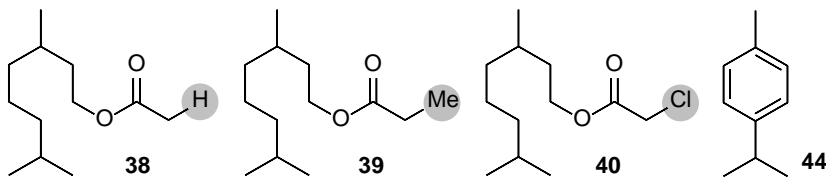

$0.5 \pm 0.2 \%$

$1.4 \pm 0.6 \%$

$2.8^{ \pm} 0.4 \%$

$0 \%$
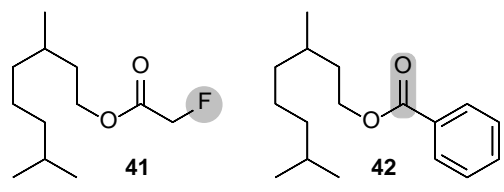

$10.0 \pm 1.4 \%$

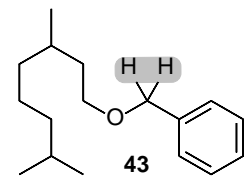

$2.6 \pm 0.6 \%$

Figure 4. Encapsulation studies. The binding affinity of the neryl substrates with different leaving groups to the capsule was estimated by determining the encapsulation degree of the corresponding inert substrate analogues. Conditions: capsule $(1.67 \mu \mathrm{mol})$ and guest $(16.7 \mu \mathrm{mol})$ in $\mathrm{CDCl}_{3}(0.50 \mathrm{~mL})$.

In the case of neryl benzoate (29), the binding of the substrate is likely enhanced by $\pi-\pi$ interactions between the phenyl ring of the leaving group and the aromatic residues of the capsule. Indeed, the substrate analog $\mathbf{4 2}$ with a benzoate group showed the highest affinity to the capsule (Figure 4). The electronic nature of the benzoate (4-fluorobenzoate, Figure $3 \mathrm{n}$ and 4methoxybenzoate, Figure 3o) does not significantly influence the selectivity of the reaction. However, the $S_{N} 1$-pathway was less favored when a bulkier benzoate (4-tert-butylbenzoate, SI-Figure 2) was introduced. Furthermore, it is noteworthy that the ester 
functionality also plays a crucial role for the observed selectivity. The replacement of the benzoate group by the benzyl ether moiety (Figure 3p) led to a promiscuous reaction. This may also be attributed to the reduced binding affinity of the benzyl substrate 43 as compared to the benzoate substrate 42 (Figure 4). The geranyl substrates did not display this pronounced effect observed for the neryl substrates, when varying the leaving group (SIFigure 3-5).

Control experiments. Several control experiments were performed to elucidate the role of capsule $\mathbf{I}$ in the cyclization reaction of GOAc (20). First, the capsule catalyst was replaced with conventional Lewis acids or Brønsted acids. This only led to complex product mixtures containing only trace amounts of cyclic products. ${ }^{12 c}$ Secondly, we investigated the cyclization reaction in the presence of the blocked capsule. It is known that the resorcinarene capsule preferentially binds cationic guests over neutral ones. ${ }^{14 \mathrm{~b}, 14 \mathrm{c}, 16}$ Tetrabutylammonium bromide (TBAB) was therefore chosen as an inhibitor due to its strong binding affinity (Table 1 , entry 2 ). In the presence of the ammonium bromide, only $4 \%$ of the substrate was consumed after 3 days. However, no formation of cyclic terpene products was observed. Next, we decided to probe the substrate recognition of the capsule by using differently sized substrates. If the substrate is only converted inside the cavity of the capsule, the smaller substrate which is more efficiently encapsulated should be converted faster than an elongated substrate derivative which features a similar reactivity. The extended version of GOAc, $n$-decyl-GOAc 45 (Table 1 ), was synthesized and subjected to a competition experiment with GOAc (20) (0.5 equiv. of each, Table 1 , entry 3 ). After 24 hours, GC analysis revealed a $81 \%$ conversion of GOAc (20) with $24 \%$ aterpinene (6) as the major product, while only $2 \%$ consumption of the bulkier substrate $\mathbf{4 5}$ could be detected. These experiments provided strong evidence that the cyclization reaction does occur within the cavity of the hexameric capsule. However, they do not completely exclude the possibility that a single resorcinarene monomer unit catalyzes the reaction. Cohen et al. reported that the hexameric capsule collapses to monomers upon addition of certain amounts of polar solvents like methanol or DMSO. ${ }^{14 \mathrm{~b}, 26}$ These solvents are able to interrupt the hydrogen-bonding network of the capsule. Following this literature precedent, the cyclization reaction of GOAc (20) was attempted in the presence of 10 equiv. DMSO (relative to the substrate, Table 1, entry 4). Indeed, no conversion was observed even after one week. Additionally, omitting the capsule catalyst also completely prevented the reaction (Table 1, entry 5). These control experiments provided strong evidence that the conversion to cyclic terpene products indeed occurs inside the capsule.

Kinetic investigations. Kinetic studies using the initial rate method were performed to clarify the mechanism of the cyclization reaction. GOAc (20) was selected as a model substrate, as its "nonstop" ${ }^{27}$ cyclization reaction resembles the corresponding biosynthetic pathway most closely. The rate of the reaction was measured to be first order in the capsule I (Figure 5a). Also first-order consumption of the substrate was observed (Figure 5b). Accordingly, the reaction obeys the following rate law: rate = $k_{o b s}[\mathrm{GOAc}][\mathbf{I}]$.
Table 1. Control experiments. Standard conditions: cyclization reactions were performed in $\mathrm{CDCl}_{3}$ at $30^{\circ} \mathrm{C}$ with a substrate (GOAc 20) concentration of $33.3 \mathrm{~mm}$ and using $10 \mathrm{~mol} \% \mathrm{I}$ as the catalyst. Commercially available $\mathrm{CDCl}_{3}$ was used without any treatment. ${ }^{a}$ A 1:1-mixture of GOAc (20) and $n$-decyl-GOAc 45 with a total concentration of $33.3 \mathrm{mM}$ was used.

\begin{tabular}{ccll}
\hline entry & \multicolumn{1}{c}{ I } & additive & conversion \\
\hline 1 & $10 \mathrm{~mol} \%$ & none & $94 \%(1 \mathrm{~d})$ \\
2 & $10 \mathrm{~mol} \%$ & $15 \mathrm{~mol} \% \mathrm{Bu}_{4} \mathrm{NBr}$ & $4 \%(3 \mathrm{~d}$, no THT product $)$ \\
$3^{\mathrm{a}}$ & $10 \mathrm{~mol} \%$ & $0.5 \mathrm{eq} 45$ & $\begin{array}{c}1 \mathrm{~d}: 81 \% \text { for GOAc }(20) \\
2 \% \text { for } 45\end{array}$ \\
4 & $10 \mathrm{~mol} \%$ & 10 eq DMSO & $0 \%(7 \mathrm{~d})$ \\
5 & none & none & $0 \%(20 \mathrm{~d})$
\end{tabular}

Rate determining step. To probe the rate determining step, activation parameters were determined by performing the cyclization reaction of GOAc (20) at different temperatures (Figure 5b). Analysis of the Eyring-plot (Figure 5d) revealed the activation parameters (Table 2$)$. The determined entropy of activation $\left(\Delta S^{\neq}\right.$ $\left.=11.0 \pm 0.3 \mathrm{cal} \mathrm{mol}^{-1} \mathrm{~K}^{-1}\right)$ indicates that the transition state of the rate determining step is more disordered than its ground state. In principle, two reaction steps could account for a positive entropy of activation. 1) The uptake of one substrate molecule would liberate two to three encapsulated solvent molecules. 2) The cleavage of the leaving group would also constitute an entropically favorable reaction. In order to differentiate between these two possibilities, we decided to examine the kinetic isotope effect. ${ }^{28}$ In case of the cleavage of the leaving group as the rate determining step, a secondary kinetic isotope effect is expected due to the change in hybridization of the methylene group. No effect should be observed in the case of a rate-determining encapsulation process. In a competition experiment, the reaction rate constant of GOAc (20) was compared with that of its deuterium analog

Table 2. Summary of activation parameters for $\mathrm{NOH}$ (18), NOAc (22), neryl chloroacetate (23) and GOAc (20). Cyclization reactions were performed in $\mathrm{CDCl}_{3}$ at $30^{\circ} \mathrm{C}$ with a substrate concentration of $33.3 \mathrm{~mm}$ using $10 \mathrm{~mol} \% \mathrm{I}$. The Gibbs free energies at $303 \mathrm{~K}$ are given. ${ }^{a}$ The cyclization reactions were performed in water-saturated $\mathrm{CDCl}_{3}$.

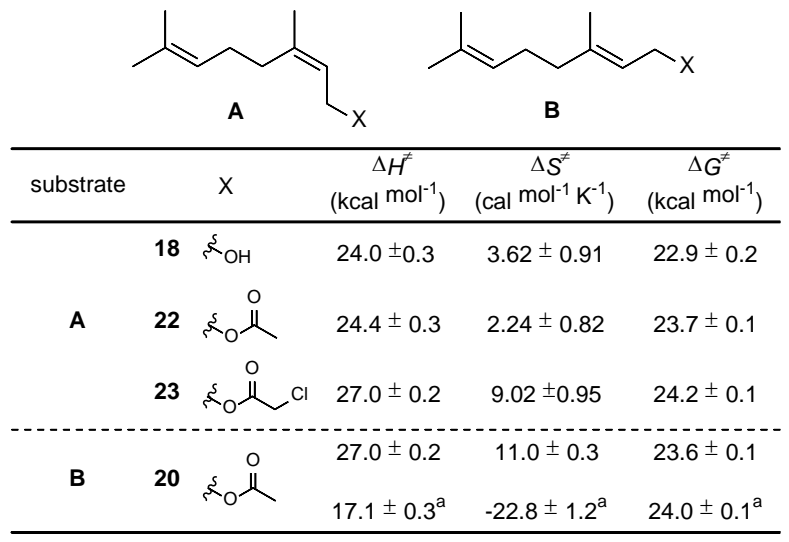



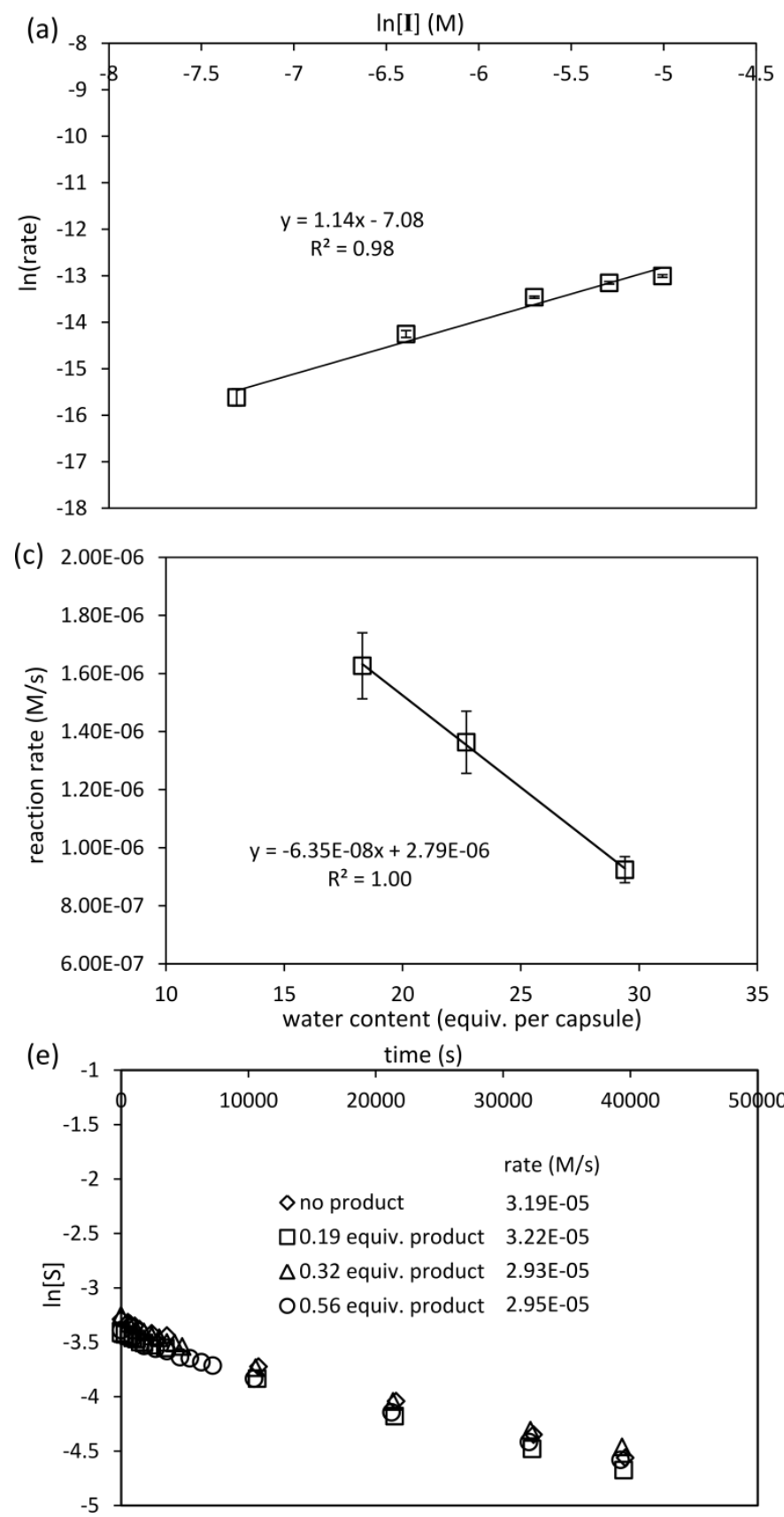

1,1-D - -GOAc (46) (Scheme 4). A normal secondary isotope effect of $k_{\mathrm{H}} / k_{\mathrm{D}}=1.22$ was determined. This clearly indicates that the cleavage of the leaving group is the rate determining step in the reaction of GOAc (20). This result also rules out the possibility of the cyclization being the rate determining step, since the change in hybridization from $\mathrm{sp}^{2}$ to $\mathrm{sp}^{3}$ at the reacting carbon atom should result in an inverse secondary kinetic isotope effect $\left(k_{\mathrm{H}} / k_{\mathrm{D}}\right.$ approx. 0.8-0.9). Also the reaction of neryl chloroacetate (23), which is believed to also react via a $S_{N} 1$-type mechanism, revealed a comparable entropy of activation $\left(\Delta S^{\mp}=9.02 \pm 0.95 \mathrm{cal}\right.$ $\left.\mathrm{mol}^{-1} \mathrm{~K}^{-1}\right)$. Intriguingly, the entropies of activation determined for the $\mathrm{S}_{\mathrm{N}} 2$-substrates $(\mathrm{NOH}, 18$ and NOAc, 22) are significantly smaller $\left(\Delta S^{\neq}=3.62 \pm 0.91 \mathrm{cal} \mathrm{mol}^{-1} \mathrm{~K}^{-1}\right.$ and $\Delta S^{\neq}=2.24 \pm 0.82 \mathrm{cal}$ $\mathrm{mol}^{-1} \mathrm{~K}^{-1}$, respectively). This difference can be rationalized by the more restricted transition state in the $S_{N} 2$-mechanism, which causes a loss in rotational degrees of freedom.
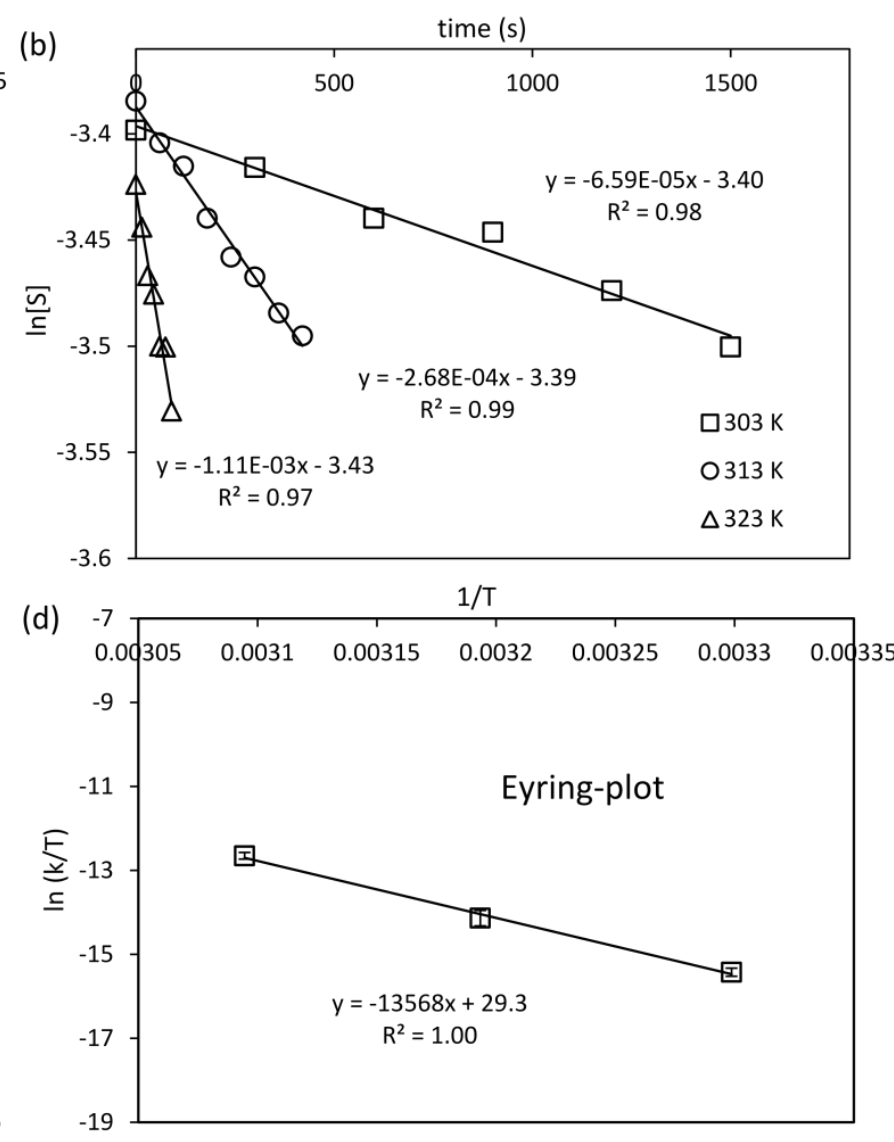

Figure 5. Kinetic data of the cyclization of GOAc (20). Rate dependence of the cyclization reaction on (a) the concentration of the catalyst I; (b) the concentration of the substrate and (c) the water content. The Eyring-plot (d) reveals that the cyclization reaction is entropy-driven. (e) The cyclization reactions performed in the presence of the major product, $\alpha$-terpinene (6, up to 0.56 equiv., relative to the substrate) display no significant attenuation of the reaction rate.

It is well known that water plays an important role in the formation of capsule I. ${ }^{29}$ The resorcinarene contains crystal water molecules, which, together with the water traces in chloroform, are necessary for the formation of the capsule in solution. Depending on the batch of resorcinarene and the water content of the chloroform employed, the samples of the resorcinarene capsule display different water contents. During the optimization of the reaction conditions, it was observed that the reaction rate was affected by the water content, and that the reaction slowed down with increasing water content (Figure 5c). It was hypothesized that the presence of excessive water could impede the activation of the substrate, since water may compete with the substrate for protonation. To learn more about this phenomenon, the primary kinetic isotope effect was studied in water-saturated chloroform (SI chapter 5.5.2). Indeed, the reaction triggered by protonation was 2.7 -fold faster than the reaction, where the substrate was activated by a deu- 
Scheme 4. Proposed mechanism for the cyclization of GOAc (20) in the resorcinarene capsule I.

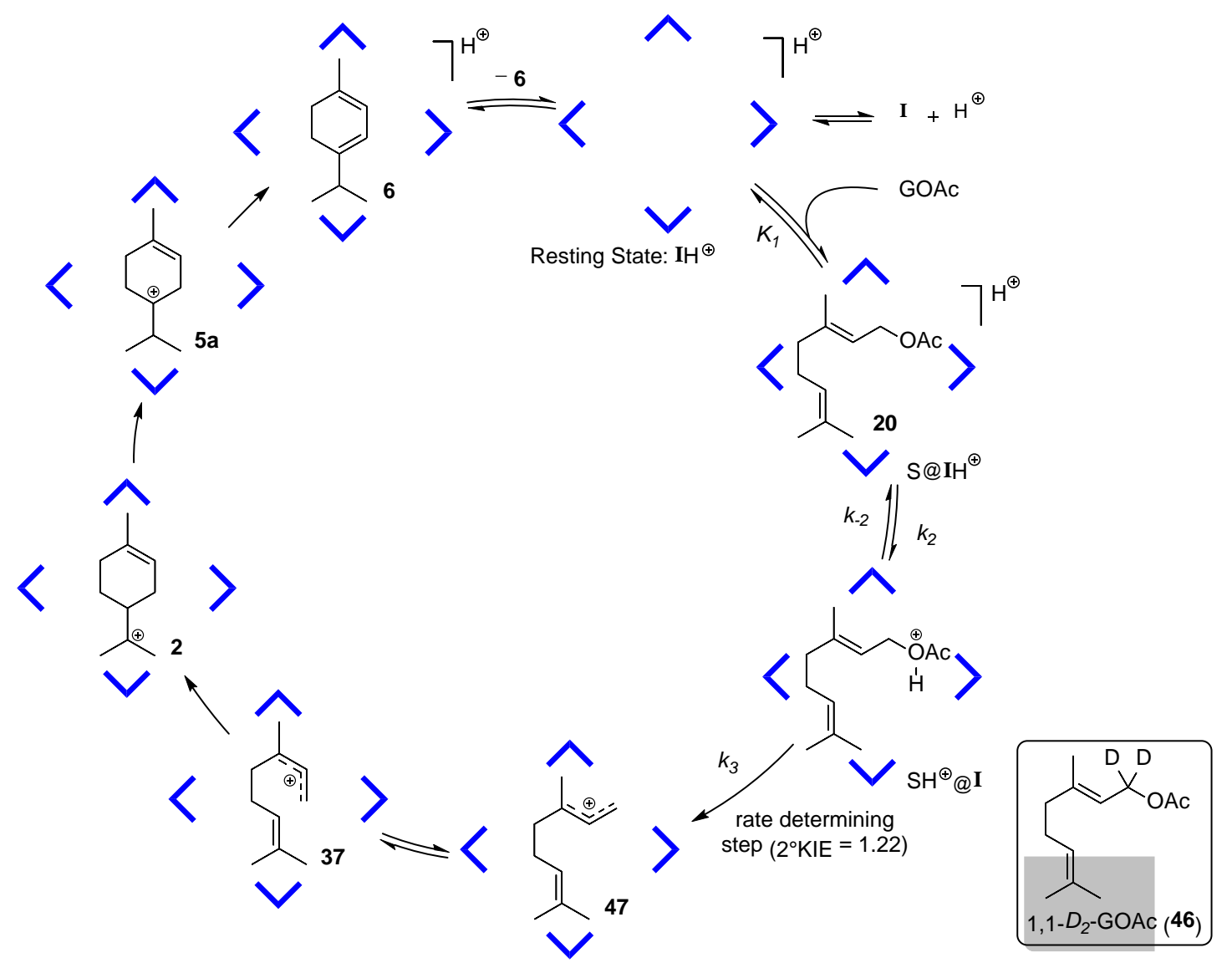

teron. Additional evidence was obtained by determining the activation parameters of the cyclization of GOAc (20) in chloroform saturated with water (Table 2 ). The negative entropy of activation $\left(\Delta S^{ \pm}=-22.8 \pm 1.2 \mathrm{cal} \mathrm{mol}^{-1} \mathrm{~K}^{-1}\right)$ reflects a higher order in the transition state than in the ground state, which is in line with a mechanism where the proton transfer is rate-limiting. In accordance with the rate attenuation, the Gibbs free energy of the reaction in chloroform saturated with water (25-29 equiv. water per capsule) is approximately $0.4 \mathrm{kcal} \mathrm{mol}^{-1} \mathrm{~K}^{-1}$ higher than that of the reaction with the standard water content (9-12 equiv. water per capsule). These results indicate that the rate determining step changes from the cleavage of the leaving group to protonation when performing the cyclization reaction in water-saturated chloroform.

Completion of the catalytic cycle. To complete the catalytic cycle, the product has to be released to regenerate the free catalyst. In many studies of supramolecular enzyme mimetics, product inhibition has been identified as a notorious obstacle. ${ }^{11 a}, 30$ To address whether capsule I suffers from this problem to some extent, the cyclization reaction of GOAc (20) was conducted in the presence of the major product $\alpha$-terpinene (6). No noteworthy reduction of the initial reaction rate could be observed with up to 0.56 equiv. of product (relative to the substrate, Figure 5e). To gain further information, binding studies were performed by using unreactive analogs of the substrate (3,7-dimethyloctyl acetate (38), Figure 4 ) and the product ( $p$-cymene, 44, Figure 4$)$. The association constant of the substrate analog was measured to be $1.57 \pm 0.62 \mathrm{M}^{-1}$. As expected, encapsulation of the product analog was nearly negligible. It is known that the resorcinarene capsule is able to stabilize encapsulated guests by forming intermolecular hydrogen bonds. ${ }^{31}$ Therefore, it is likely that the relatively polar leaving group (alcohol or ester group) of the substrate serves as the recognition motif, providing the driving force for the displacement of the product by a substrate molecule.

Derivation of the rate law. Based on the kinetic investigations, the following kinetic model was established for the reaction of GOAc (20, Scheme 4): the capsule is protonated by $\mathrm{HCl}$ to form the catalytically active species $\mathrm{IH}^{+}$(which is likely the resting state of the catalyst, as observed by ${ }^{1} \mathrm{H}$ NMR spectroscopy). After the fast encapsulation pre-equilibrium, a proton is transferred from the protonated capsule to the bound substrate, leading to the formation of the steady state intermediate $\mathrm{SH}^{+} @ \mathrm{I}$. The complex $\mathrm{SH}^{+} @ \mathrm{I}$ then undergoes the rate-limiting cleavage of the leaving group and subsequent cationic cascade reactions to yield product 6. Finally, the product is expelled to close the catalytic cycle. Based on these considerations, the rate law could be derived by applying the steady-state approximation to the intermediate $\mathrm{SH}^{+} @ \mathrm{I}$ (for the derivation of the rate law, see SI chapter 5.6). The obtained rate law is in excellent agreement with the measured kinetic data regarding the rate dependence of the reaction on the concentration of capsule I and the substrate.

Rate $=\frac{K_{1} k_{2} k_{3}}{k_{-2}+k_{3}}[\mathrm{I}][\mathrm{S}]$ 


\section{Conclusion}

We herein presented detailed investigations into the tail-to-head terpene cyclization catalyzed by the resorcinarene capsule I. A selective cyclization reaction was achieved by tuning the nature of the leaving group. Furthermore, the mechanism of the cyclization reaction was elucidated. It was found that traces of acid formed by photodegradation of the employed solvent serve as an important co-catalyst which is responsible for the activation of the substrate. Control experiments clearly showed that the synergistic interplay between the proton and the supramolecular capsule is essential for the successful tail-to-head terpene cyclization. Kinetic analysis suggests that, under the standard reaction conditions, the cleavage of the leaving group is the rate-determining step. In watersaturated chloroform, however, protonation of the bound substrate is the slowest step. These studies demonstrate that a relatively simple aromatic cavity is capable of catalyzing the challenging tail-to-head terpene cyclization reaction in a selective fashion. Synthesis of more complex terpene natural products utilizing this strategy is currently ongoing in our laboratories.

\section{ASSOCIATED CONTENT}

Supporting Information. This material is available free of charge via the Internet at http://pubs.acs.org.

\section{AUTHOR INFORMATION}

\section{Corresponding Author}

konrad.tiefenbacher@unibas.ch / tkonrad@ethz.ch

\section{Notes}

The authors declare no competing financial interest.

\section{ACKNOWLEDGMENT}

This work was supported by funding from the European Research Council Horizon 2020 Programme [ERC Starting grant 714620TERPENECAT], the Swiss National Science Foundation as part of the NCCR Molecular Systems Engineering and the Bayerische Akademie der Wissenschaften (Junges Kolleg). We thank Prof. Dr. Wolfgang Eisenreich (Technische Universität München) for the help with ${ }^{2} \mathrm{H}$ NMR measurement. Dr. Ingo Schnapperelle is acknowledged for help with GC-MS (SIM) measurements.

\section{REFERENCES}

1. (a) Croteau, R., Chem. Rev. 1987, 87, 929-954; (b) Cane, D. E., Chem. Rev. 1990, 90, 1089-1103; (c) Christianson, D. W., Chem. Rev. 2006, 106, 3412-3442; (d) Degenhardt, J.; Köllner, T. G.; Gershenzon, J., Phytochemistry 2009, 70, 1621-1637; (e) Dickschat, J. S., Nat. Prod. Rep. 2011, 28, 1917-1936; (f) Miller, D. J.; Allemann, R. K., Nat. Prod. Rep. 2012, 29, 60-71; (g) Dickschat, J. S., Nat. Prod. Rep. 2016, 33, 87-110. 2. Paddon, C. J.; Westfall, P. J.; Pitera, D. J.; Benjamin, K.; Fisher, K.; McPhee, D.; Leavell, M. D.; Tai, A.; Main, A.; Eng, D.; Polichuk, D. R.; Teoh, K. H.; Reed, D. W.; Treynor, T.; Lenihan, J.; Jiang, H.; Fleck, M.; Bajad, S.; Dang, G.; Dengrove, D.; Diola, D.; Dorin, G.; Ellens, K. W.; Fickes, S.; Galazzo, J.; Gaucher, S. P.; Geistlinger, T.; Henry, R.; Hepp, M.; Horning, T.; Iqbal, T.; Kizer, L.; Lieu, B.; Melis, D.; Moss, N.; Regentin, R.; Secrest, S.; Tsuruta, H.; Vazquez, R.; Westblade, L. F.; Xu, L.; Yu, M.; Zhang, Y.; Zhao, L.; Lievense, J.; Covello, P. S.; Keasling, J. D.; Reiling, K. K.; Renninger, N. S.; Newman, J. D., Nature 2013, 496, 528532 .

3. Kingston, D. G. I., J. Nat. Prod. 2000, 63, 726-734.
4. Malik, S.; Cusidó, R. M.; Mirjalili, M. H.; Moyano, E.; Palazón, J.; Bonfill, M., Process Biochem. 201 1, 46, 23-34.

5. Wendt, K. U.; Schulz, G. E., Structure 1998, 6, 127-133.

6. Pronin, S. V.; Shenvi, R. A., Nat. Chem. 2012, 4, 915-920.

7. Yoder, R. A.; Johnston, J. N., Chem. Rev. 2005, 105, 4730-4756.

8. (a) Pluth, M. D.; Bergman, R. G.; Raymond, K. N., Acc. Chem. Res. 2009, 42, 1650-1659; (b) Yoshizawa, M.; Fujita, M., Bull. Chem. Soc. Jpn. 2010, 83, 609-618; (c) Ronson, T. K.; Zarra, S.; Black, S. P.; Nitschke, J. R., Chem. Commun. 2013, 49, 2476-2490; (d) Han, M.; Engelhard, D. M.; Clever, G. H., Chem. Soc. Rev. 2014, 43, 1848-1860; (e) Zhang, G.; Mastalerz, M., Chem. Soc. Rev. 2014, 43, 1934-1947; (f) Leenders, S. H. A. M.; Gramage-Doria, R.; de Bruin, B.; Reek, J. N. H., Chem. Soc. Rev. 2015, 44, 433-448.

9. (a) Rebek, J., Acc. Chem. Res. 2009, 42, 1660-1668; (b) Ajami, D.; Rebek, J., Acc. Chem. Res. 2012, 46, 990-999; (c) Ajami, D.; Liu, L.; Rebek Jr, J., Chem. Soc. Rev. 2015, 44, 490-499.

10. Jordan, J. H.; Gibb, B. C., Chem. Soc. Rev. 2014, 44, 547-585.

11. (a) Yoshizawa, M.; Klosterman, J. K.; Fujita, M., Angew. Chem. Int. Ed. 2009, 48, 3418-3438; (b) Meeuwissen, J.; Reek, J. N. H., Nat Chem 2010, 2, 615-621; (c) Marchetti, L.; Levine, M., ACS Catal. 2011, 1, 1090-1118; (d) Wiester, M. J.; Ulmann, P. A.; Mirkin, C. A., Angew. Chem. Int. Ed. 2011, 50, 114-137; (e) Raynal, M.; Ballester, P.; VidalFerran, A.; van Leeuwen, P. W. N. M., Chem. Soc. Rev. 2014, 43, 17341787; (f) Brown, C. J.; Toste, F. D.; Bergman, R. G.; Raymond, K. N., Chem. Rev. 2015, 115, 3012-3035; (g) Zarra, S.; Wood, D. M.; Roberts, D. A.; Nitschke, J. R., Chem. Soc. Rev. 2015, 44, 419-432; (h) Catti, L.; Zhang, Q.; Tiefenbacher, K., Synthesis 2016, 48, 313-328; (i) Catti, L.; Zhang, Q.; Tiefenbacher, K., Chem. Eur. J. 2016, 22, 9060-9066. For recent examples see: (j) Cullen, W.; Misuraca, M. C.; Hunter, C. A.; Williams, N. H.; Ward, M. D., Nat. Chem. 2016, 8, 231-236; (k) Levin, M. D.; Kaphan, D. M.; Hong, C. M.; Bergman, R. G.; Raymond, K. N.; Toste, F. D., J. Am. Chem. Soc. 2016, 138, 9682-9693; (1) Jans, A. C. H.; Gómez-Suárez, A.; Nolan, S. P.; Reek, J. N. H., Chem. Eur. J. 2016, 22, 14836-14839; (m) Kuijpers, P. F.; Otte, M.; Dürr, M.; IvanovićBurmazović, I.; Reek, J. N. H.; de Bruin, B., ACS Catal. 2016, 6, 31063112; (n) Wang, Q.-Q.; Gonell, S.; Leenders, S. H. A. M.; Dürr, M.; Ivanović-Burmazović, I.; Reek, J. N. H., Nat. Chem. 2016, 8, 225-230; (o) Ueda, Y.; Ito, H.; Fujita, D.; Fujita, M., J. Am. Chem. Soc. 2017, asap.

12. (a) Zhang, Q.; Tiefenbacher, K., J. Am. Chem. Soc. 2013, 135, 1621316219; (b) Catti, L.; Tiefenbacher, K., Chem. Commun. 2015, 51, $892-$ 894; (c) Zhang, Q.; Tiefenbacher, K., Nat. Chem. 2015, 7, 197-202; (d) Bräuer, T. M.; Zhang, Q.; Tiefenbacher, K., Angew. Chem. Int. Ed. 2016, 55, 7698-7701; (e) Catti, L.; Pöthig, A.; Tiefenbacher, K., Adv. Synth. Catal. 2017, 359, 1331-1338.

13. (a) Bianchini, G.; La Sorella, G.; Canever, N.; Scarso, A.; Strukul, G., Chem. Commun. 2013, 49, 5322-5324; (b) Giust, S.; La Sorella, G.; Sperni, L.; Fabris, F.; Strukul, G.; Scarso, A., Asian J. Org. Chem. 2015, 4, 217-220; (c) La Sorella, G.; Sperni, L.; Strukul, G.; Scarso, A., ChemCatChem 2015, 7, 291-296; (d) Caneva, T.; Sperni, L.; Strukul, G.; Scarso, A., RSC Adv. 2016, 6, 83505-83509; (e) Caneva, T.; Sperni, L.; Strukul, G.; Scarso, A., RSC Adv. 2016, 6 (87), 83505-83509; (f) La Sorella, G.; Sperni, L.; Ballester, P.; Strukul, G.; Scarso, A., Catal. Sci. Technol. 2016, 6, 6031-6036; (g) La Sorella, G.; Sperni, L.; Strukul, G.; Scarso, A., Adv. Synth. Catal. 2016, 358, $3443-3449$.

14. (a) MacGillivray, L. R.; Atwood, J. L., Nature 1997, 389, 469-472; (b) Avram, L.; Cohen, Y., J. Am. Chem. Soc. 2002, 124, 15148-15149; (c) Avram, L.; Cohen, Y.; Rebek, J., Chem. Commun. 2011, 47, 5368-5375. 15. Yamanaka, M.; Shivanyuk, A.; Rebek, J., J. Am. Chem. Soc. 2004, 126, 2939-2943.

16. Shivanyuk, A.; Rebek, J., Proc. Natl. Acad. Sci. U.S.A. 2001, 98, $7662-$ 7665.

17. (a) Leão Lana, E. J.; da Silva Rocha, K. A.; Kozhevnikov, I. V.; Gusevskaya, E. V., J. Mol. Catal. A: Chem. 2006, 259, 99-102; (b) Kelly, B. D.; Allen, J. M.; Tundel, R. E.; Lambert, T. H., Org. Lett. 2009, 11, 1381-1383.

18. Bugarčić, Z. M.; Dunkić, J. D.; Mojsilović, B. M., Heteroat. Chem. 2004, 15, 468-470.

19. Wise, M. L.; Urbansky, M.; Helms, G. L.; Coates, R. M.; Croteau, R., J. 
Am. Chem. Soc. 2002, 124, 8546-8547.

20. Croteau, R. B.; Shaskus, J. J.; Renstrom, B.; Felton, N. M.; Cane, D. E.; Saito, A.; Chang, C., Biochemistry 1985, 24, 7077-7085.

21. Croteau, R., Arch. Biochem. Biophys. 1986, 251, 777-782.

22. Avram, L.; Cohen, Y., Org. Lett. 2003, 5, 3329-3332.

23. Evan-Salem, T.; Baruch, I.; Avram, L.; Cohen, Y.; Palmer, L. C.; Rebek, J., Proc. Natl. Acad. Sci. U.S.A. 2006, 103, 12296-12300.

24. The protons greatly outnumber the added deuteron. For a resorcinarene capsule sample with 10 equiv. water, the H:D-ratio is 99:1, As a result, the observed reaction was dominantly triggered by protonation and therefore displayed very similar reaction rate as the reaction where protons function as the sole activation source.

25. Richter, M., Nat. Prod. Rep. 2013, 30, 1324-1345.

26. Zhang, Q.; Catti, L.; Kaila, V. R. I.; Tiefenbacher, K., Chem. Sci. 2017,
8, 1653-1657.

27. Eschenmoser, A.; Ruzicka, L.; Jeger, O.; Arigoni, D., Helv. Chim. Acta 1955, 38, 1890-1904.

28. (a) Wiberg, K. B., Chem. Rev. 1955, 55, 713-743; (b) Giagou, T.; Meyer, M. P., Chem. Eur. J. 2010, 16, 10616-10628.

29. Avram, L.; Cohen, Y., Org. Lett. 2002, 4, 4365-4368.

30. Koblenz, T. S.; Wassenaar, J.; Reek, J. N. H., Chem. Soc. Rev. 2008, 37, 247-262.

31. (a) Palmer, L. C.; Shivanyuk, A.; Yamanaka, M.; Rebek, J. J., Chem. Commun. 2005, 857-858; (b) Slovak, S.; Avram, L.; Cohen, Y., Angew. Chem. Int. Ed. 2010, 49, 428-431; (c) Slovak, S.; Cohen, Y., Chem. Eur. J. 2012, 18, 8515-8520. 